\title{
Culture and Antibiotic Sensitivity of Escherichia coli Isolated from Patients with Urinary Tract Infections (UTI) in Jessore City
}

\author{
Md. Tanvir Islam ${ }^{1 *}$, Sunzid Ahmed ${ }^{1}$, Marufa Nasreen ${ }^{2}$, Nigarin Sultana ${ }^{1}$ \\ ${ }^{I}$ Department of Microbiology, Jessore Science \& Technology University, Jessore 7408, Bangladesh \\ ${ }^{2}$ Department of Biotechnology \& Genetic Engineering, Mawlana Bhashani Science \& Technology University, \\ Tangail 1902, Bangladesh
}

\begin{abstract}
Urinary tract infection is caused by the presence and growth of microorganisms in the urinary tract, is perhaps the single commonest bacterial infection of mankind. The present study was carried out to identify Escherichia coli from urinary tract infected patients those come to a community hospital in Jessore city. For the confirmation of the presence of this disease causing agent various cultural and biochemical techniques were performed. A total of 87 clinically suspected patients having urinary tract infection were studied, 50 were found to be culture positive. Among the positive cultures, 30 (60\%) isolates were infected with Escherichia coli. The study showed that the most susceptible group for urinary tract infection ranges between 16-45 years of age, as this group comprised of $15(50 \%)$ individuals. Antibiotic susceptibility for all 30 isolates was determined against locally available eleven drugs. High resistance rates were observed against most of the antibiotics examined here. Amoxycilin stood to be the most resistant type of antibiotic (90\%), followed by nalidixic acid $(57 \%)$, cephlexin (50\%), ciprofloxacin (37\%), ceftriaxone (27\%), doxycycline (24\%) and cefixime (20\%). Gentamycin and nitrofurantoin got lower resistance rates at $14 \%$ and $3 \%$ respectively, but resistance to netilmycine was not found among all 30 isolates. Multidrug resistance pattern of the isolated organism was also observed in this present study.
\end{abstract}

Keywords: Antibiotics, Escherichia coli, Multidrug Resistance, Urinary tract infection.

\section{INTRODUCTION}

Urinary tract infection (UTI) involves the infection of kidneys, ureters, bladder or urethra by pathogenic invasion of urinary tract, which ultimately leads to an inflammatory response of the urothelium. The most common symptoms of UTI are burning with urination and having to urinate frequently in the absence of significant pain ${ }^{[1]}$. Numerous reports have suggested that UTI can occur in both male and female patients of any age having bacterial count as low as 100 colony forming unit (CFU) per milliliters (ml) in urine ${ }^{[2]}$. Young sexually active women however believed to be more affected than males except at the extremes of life. Member of the Enterobacteriaceae especially Escherichia coli are the cause of the majority of UTI. Uropathogenic E. coli causes $90 \%$ of the UTIs in anatomically normal, unobstructed urinary tracts ${ }^{[3]}$.

Treatment of UTIs varies according to the age of the patient, sex, underlined disease, infecting agent and whether there is lower or upper urinary tract involvement. Antimicrobial agents among the most frequently prescribed drugs in nursing home are most common for UTI. A complicated UTI is more difficult to treat and usually requires more aggressive evaluation, treatment and follow-up ${ }^{[4]}$. Unfortunately, with each passing decade, emergent strains of bacteria that defy not only single but also multiple antibiotics have become increasingly common. The spread of microbial drug resistance impairs the efficacy of antimicrobial agents and results in substantial increased illness and death rates ${ }^{[5]}$. The more an antibiotic is used, the more the bacteria become resistant to it. Bacteria can acquire multiple different genes for resistance, making them resistant to multiple families of antibiotic drugs. Such multiple drug resistant strains present the greatest clinical challenge.

The purpose of this study is to identify Escherichia coli as etiological agent of UTI in persons of different age groups and to investigate their responses against locally available antibiotics commonly prescribed by the physicians.

\section{MATERials AND Methods}

This study was carried out among the patients who came with UTI symptoms to a community hospital in Jessore city in the month of May 2013. A total 87 subjects were enrolled in this study and midstream morning urine samples were collected aseptically for culture. The name, age and sex of the patients were properly labeled on the sterile universal containers immediately after collecting the samples and carried to the laboratory. Before culturing the sample, containers were stored in the refrigerator at $4^{0} \mathrm{C}$ and were analyzed without much delay to avoid any alteration. $100 \mu \mathrm{l}$ of specimen was inoculated on MacConkey agar and Eosine Methylene Blue (EMB) agar plate. The plates were then incubated aerobically at $37^{\circ} \mathrm{C}$ for 24 hours in inverted position. Primary bacterial identification was done by observing the overnight culture. Standard biochemical 
tests were also performed in order to confirm the identity of Escherichia coli ${ }^{[6]}$. Bacterial susceptibility was determined by the Kirby-Bauer disc diffusion method using antibiotic containing discs from Oxoid Ltd, UK ${ }^{[7]}$. Eleven types of antibiotic discs were used in this study. Those were Amoxyciline (AML), Doxycycline (DO), Nalidixic acid (NAL), Ciprofloxacin (CIP), Cephlexin (CL), Cefradine (CEF), Ceftriaxone (CRO), Cefixime (CFM), Gentamycin (GEN), Netilmycin (NET), Nitrofurantoin (NIT). Antibcaterial concentration used was 30 $\mu \mathrm{g}$ except GEN $(10 \mu \mathrm{g})$, NIT $(100 \mu \mathrm{g})$, and CIP $(5 \mu \mathrm{g})$. The zone diameters for individual antimicrobial agents were translated into susceptible and resistant categories ${ }^{[8]}$.

\section{RESULTS AND DISCUSSION}

A series of studies were carried out on the various microbiological parameters of mid stream urine sample. E. coli was isolated from 30 UTI samples among all 87. The cultural characteristics of E. coli colonies grown on MacConkey agar and EMB agar plates were observed as round shaped smooth colonies, moderate in size. The characteristic colony color as red or pink was observed on MacConkey agar plates, and metallic green sheen on EMB agar plates. Several biochemical tests were done for further identification. All 30 isolates showed KIA (ve+), Motility (ve+), Indole (ve+), Urease (ve+), Citrate (ve-) and Oxidase (ve-).

The study showed that 30 individuals got UTI among all 87 gave urine sample. $50 \%$ individuals, aging between 15-45 years are more susceptible to UTI infection. Individual's age $>45$ years and $<15$ years was found $33.33 \%$ and $16.67 \%$ susceptibility respectively (Table 1 ).

Table 1: Incidence of E. coli isolated from urine sample.

\begin{tabular}{cccc}
\hline Age & Male & Female & Male + Female \\
\hline Below 15 & 05 & - & 05 \\
16-45 & - & 15 & 15 \\
Above 45 & - & 10 & 10 \\
\hline
\end{tabular}

Antimicrobial sensitivity (Table 2) for all 30 infected isolates was determined by the Kirby-Bauer disc diffusion method. High resistance rates (Fig: 1) were observed for amoxycilin (90\%), nalidixic acid (57\%), cephlexin (50\%), ciprofloxacin (37\%), ceftriaxone (27\%), doxycycline (24\%), cefixime (20\%). Lower resistance rates were observed for gentamicin and nitrofurantoin, 14\% and 3\% respectively. All 30 isolates were observed totally sensitive against the antibiotic netilmycin.

Table 2: Result of antibiotic sensitivity of 30 isolates

\begin{tabular}{ccc}
\hline Antibiotics & No. of Resistant Isolates & No. of Susceptible Isolates \\
\hline Amoxyciline & 27 & 03 \\
Nalidixic Acid & 17 & 13 \\
Cephalexin & 15 & 15 \\
Cefradin & 15 & 15 \\
Ciprofloxacin & 11 & 19 \\
Ceftriaxone & 8 & 22 \\
Doxycycline & 7 & 23 \\
Cefixime & 6 & 24 \\
Gentamycine & 4 & 26 \\
Nitrofurantoin & 1 & 29 \\
Netilmycine & 0 & 30 \\
\hline
\end{tabular}

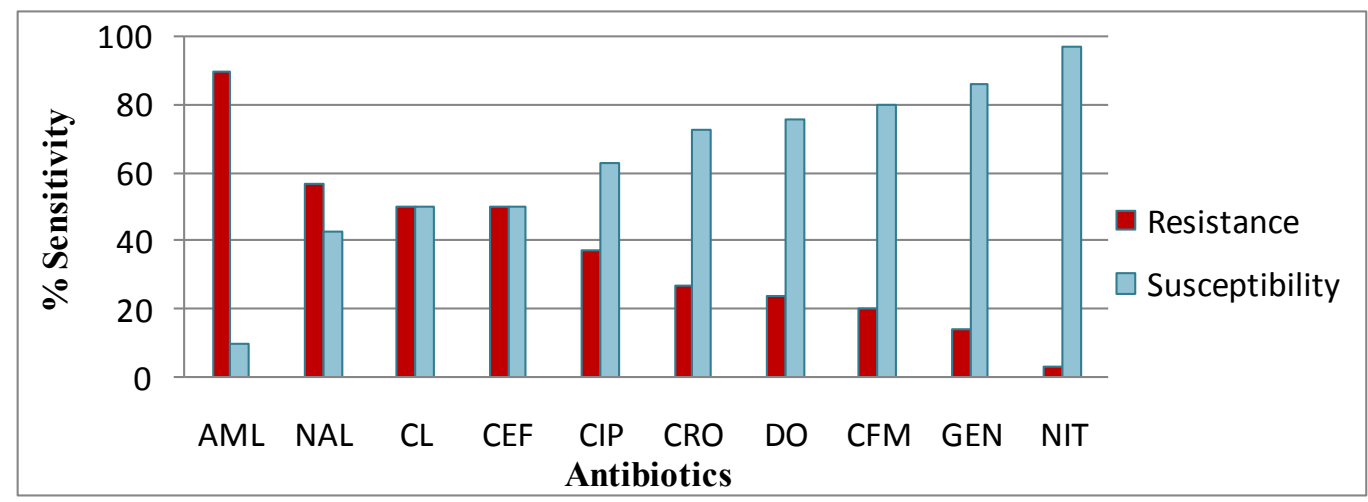

Figure 1: antibiotic sensitivity pattern of the $E$. coli isolates $(\mathrm{n}=30)$ from UTI patients. 
Multidrug resistant pattern (Table 3) was analyzed as it was a common behavior in most of the organisms isolated from urine. Among the 30 isolates 6, 3, 4, 4, 5, 3, 3 isolates were found resistant to R1, R2, $\mathrm{R} 3, \mathrm{R} 4, \mathrm{R} 5, \mathrm{R} 6, \mathrm{R} 7$ combination. 1 isolate was resistant to 8 antibiotics (R8 combination), which was maximum (Fig: 2). But there found 1 isolate which was totally susceptible to all 11 antibiotics.

Table 3: Multidrug resistance pattern of E. coli $(\mathrm{n}=30)$ from UTI patients

\begin{tabular}{|c|c|c|}
\hline Antibiotic Combination Name & Name of Antibiotics & No. of Resistant Isolates \\
\hline $\mathrm{R} 1$ & AML & 6 \\
\hline $\mathrm{R} 4$ & $\begin{array}{c}\mathrm{CL}+\mathrm{CEF}+\mathrm{AML}+\mathrm{CRO} \\
\mathrm{CL}+\mathrm{CEF}+\mathrm{AML}+\mathrm{NAL} \mathrm{CIP}+\mathrm{NAL}+\mathrm{AML}+\mathrm{DO}\end{array}$ & $\begin{array}{l}1 \\
1 \\
2\end{array}$ \\
\hline R6 & $\begin{array}{c}\mathrm{CL}+\mathrm{CEF}+\mathrm{CIP}+\mathrm{NAL}+\mathrm{AML}+\mathrm{DO} \\
\mathrm{CL}+\mathrm{CEF}+\mathrm{NIT}+\mathrm{NAL}+\mathrm{AML}+\mathrm{GEN} \\
\mathrm{CL}+\mathrm{CEF}+\mathrm{CFM}+\mathrm{CRO}+\mathrm{AML}+\mathrm{DO} \\
\end{array}$ & $\begin{array}{l}1 \\
1 \\
1\end{array}$ \\
\hline R7 & $\begin{array}{l}\mathrm{CL}+\mathrm{CEF}+\mathrm{CIP}+\mathrm{CRO}+\mathrm{AML}+\mathrm{NAL}+\mathrm{GEN} \\
\mathrm{CL}+\mathrm{CEF}+\mathrm{CRO}+\mathrm{CFM}+\mathrm{AML}+\mathrm{GEN}+\mathrm{DO} \\
\mathrm{CAL}+\mathrm{CEF}+\mathrm{CIP}+\mathrm{CFM}+\mathrm{CRO}+\mathrm{AML}+\mathrm{DO}\end{array}$ & $\begin{array}{l}1 \\
1 \\
1\end{array}$ \\
\hline $\mathrm{R} 8$ & $\mathrm{CAL}+\mathrm{CEF}+\mathrm{CIP}+\mathrm{CFM}+\mathrm{CRO}+\mathrm{AML}+\mathrm{NAL}+\mathrm{GEN}$ & 1 \\
\hline
\end{tabular}

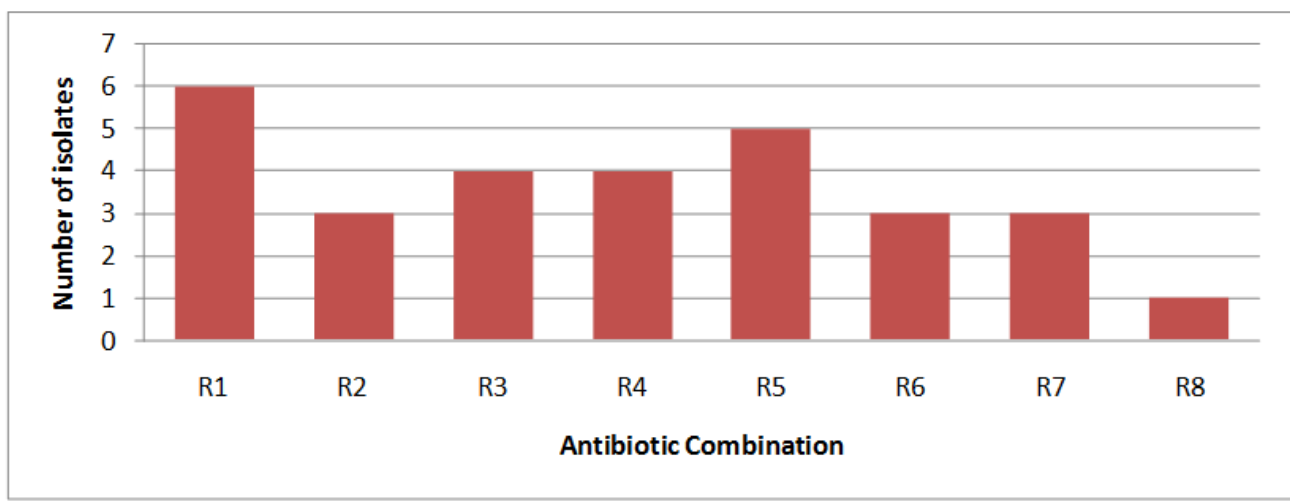

Figure 2: multidrug resistance pattern of $E$. coli isolates $(n=30)$ recovered from UTI patients.

UTI ranks as one of the most important causes of morbidity even today in the developing countries like Bangladesh ${ }^{[9]}$. This may be attributed to abuse of chemotherapeutic agents and most importantly ignorance of people and little or no prevention measure. The present study had been investigating the prevalence of $E$. coli in UTI, as well as their drug resistant pattern.

A total of 87 clinically suspected patients having urinary tract infection including children, teenagers and women were studied; 30 samples showed $E$. coli as the causative agent of UTI. Although UTI affects all age groups, many scientists proved that, UTIs are most frequent bacterial infection in female ${ }^{[10]}$. They occur between the age 16 and 45 years. The present study also supports this likeliness as 50\% $(\mathrm{n}=15)$ positive individuals were between 16-45 years. It was also found that women aging greater than 45 years also susceptible to E. coli; $33.33 \%(\mathrm{n}=10)$ positive individuals were identified. Women are more prone to UTIs than men because, in females the urethra is much shorter and closure to anus ${ }^{[11]} .16 .66 \%(n=5)$ positive individuals were found below 15 years, where conditions may be due to the poor personal hygiene practices.

Several studies clearly demonstrated an increasing antibiotic resistance in E. coli causing both community and nosocomially acquired UTIs ${ }^{[12]}$. In treatment of UTIs, trimethoprim/sulfamethoxazole is the 
recommended drug in settings where the prevalence of resistance is, $10-20 \%$ according to the Infectious Disease Society of America (IDSA) guidelines ${ }^{[13]}$. To assess the breadth of multidrug resistance among uropathogenic E. coli, samples were taken during the month of May 2013 from a community hospital in Jessore city. The present study showed that all E. coli isolated were more or less multidrug resistant. $90 \%$ E. coli isolates were found to be resistant against amoxycilin, which was the first choice of drug used against UTI. When they become resistant the next group of antibiotic to treat UTI infection has been using until now, is quinolone group; among which nalidixic acid was first. But the present study alarmingly showed $57 \%$ E. coli isolates were already resistant against nalidixic acid. 50\% was resistant against both of cephlexin and cefradine. Apart from these, $37 \%$ isolates were found resistant against ciprofloxacin. A study in Taiwan found that, prior exposure to ciprofloxacin raises the risk of resistance ${ }^{[14]}$. The isolates showed $27 \%, 24 \%$ and $20 \%$ resistance against ceftriaxone, doxycycline and cefixime respectively. Lower resistance rates were observed for gentamycine $(14 \%)$ and nitrofurantoin (3\%). Interestingly, resistance to netilmycine was not found towards all the 30 isolates.

In this study $10 \%$ isolates were found which are resistant against seven antibiotics amoxyciline, nalidixic acid, doxycycline, ciprofloxacin, cefalexin, cefradin, and gentamycine. High levels of resistance were observed for amoxyciline, nalidixic acid, cephalexin and cephradine; which had been reported as having high percentage of resistance for a lot of clinically isolated microorganisms and the resistance rate is rising day by day.

\section{CONCLUSION}

Antibiotic resistance is a serious and growing phenomenon in contemporary medicine and has emerged as one of the pre-eminent public health concerns of the 21 st century. In our region, uncontrolled consumption of these common antibiotics during the past decade influenced the spreading of resistance property among the causative agents ${ }^{[15]}$. Inappropriate antibacterial treatment and abuse of antibiotics have also contributed to the emergence of antibacterial-resistant bacteria. Self prescription of antibacterials is an example of antibiotic abuse ${ }^{[16]}$. High resistance against these commonly used antibacterials is certainly worrisome. Therefore these drugs should no longer be prescribed as initial empirical therapy but unfortunately these antibiotics are yet being prescribed as first line drugs in the developing countries.

\section{REFERENCES}

[1]. L Nicolle, Uncomplicated urinary tract infection in adults including uncomplicated pyelonephritis, Uro Clin NorAme,35(1),2008, 112.

[2]. K Akinyemi, S Alabi, N Taiwo, E Omonighehin, Antimicrobial susceptibility pattern and plasmid profile of pathogenic bacteria isolated from subjects with urinary tract infections in Lagos, Nigeria. Nig. Qt J Hosp. Med, (1,) 1997, 7-11.

[3]. K Todar, Pathogenic Escherichia coli, Todar's Online Text Book of Bacteriology (University of Wisconsin Madison, 2008)

[4]. Bryan, S Charles, Infectious diseases in primary care (Philadelphia: W.B. Saunders 2002).

[5]. D Byarugaba, A view on antimicrobial resistance in developing countries and responsible risk factors, .Int. J Ant Agents, 24, 2004,105-10.

[6]. Cappuccino, J. G. and N. Sherman. (Ed.), Microbiology- A Laboratory Manual. 4(The Benjamin/Cummings Publishing Co., Inc., Menlo Park, California, 1996.)

[7]. A Bauer, W Kirby, W Sherns et.al., Antibiotic susceptibility testing by a standardized single disc method, Ame J Clin Pathol, 1966, 45:493-496.

[8]. MJ Ferraro, WA Craig and MN Dudley. (Ed.), Performance standards for antimicrobial susceptibility testing NCCL informational supplement, 11(NCCLS, Pennsylvania, USA, 2001.)

[9]. HS Jamshed, Antimicrobial sensitivity to E. coli isolated in urinary tract infection in women of childbearing age. Mym Med J (1), $1992,45-50$

[10]. R Colgan, M Williams, Diagnosis and treatment of acute uncomplicated cystitis, .Ame fam phys 84(7), 2011,771-6.

[11]. EJ Dielubanza, AJ Schaeffer, Urinary tract infections in women, The Med clin Nor Ame 95(1), 2011, 27-41.

[12]. AC Gales, HS Sader, RN Jones, Urinary tract infection trends in Latin American hospitals, Diag Microb Infect Dis 44, 2000, 28999.

[13]. MJ Zervos, E Hershberger, DP Nicolau, DJ Ritchie, LK Blackner, EA Coyle, Relationship between fluoroquinolone use and changes in susceptibility to fluoroquinolones of selected pathogens in 10 United States teaching hospitals, Clin Inf Dis, (37), 2003. 1643-8.

[14]. S Song, Antibiotic resistance mechanisms of Escherichia coli isolates from urinary specimens. Korean J. Lab. Med. 29 (1),2009, 1724.

[15]. SL Hillier, JT Magee, AJ Howard and SR Palmer, How strong is the evidence that antibiotic use is risk factor for antibioticresistant, community acquired urinary tract infection? J. Antimicrob. Chemother, (50), 2002, 241-247.

[16]. E Larson, Community factors in the development of antibiotic resistance, Annu Rev Public Health (28), $2007,435-447$. 